\title{
Changes in Endogenous Dopamine Induced by Methylphenidate Predict Functional Connectivity in Nonhuman Primates
}

\author{
Rasmus M. Birn, ${ }^{1,4 *}$ Alexander K. Converse, ${ }^{2 *}$ Abigail Z. Rajala, ${ }^{3 *}$ Andrew L. Alexander, ${ }^{1,3,4}$ Walter F. Block, ${ }^{4,5}$ \\ Alan B. McMillan, ${ }^{6}$ Bradley T. Christian, ${ }^{2,4}$ Caitlynn N. Filla, ${ }^{3}$ Dhanabalan Murali, ${ }^{4}$ Samuel A. Hurley, ${ }^{6}$ Rick L. Jenison, ${ }^{3,7}$ \\ and Luis C. Populin ${ }^{3}$ \\ ${ }^{1}$ Department of Psychiatry, University of Wisconsin-Madison, Madison, Wisconsin 53719, ${ }^{2}$ Waisman Center, University of Wisconsin-Madison, Madison, \\ Wisconsin 53705, ${ }^{3}$ Department of Neuroscience, University of Wisconsin-Madison, Madison, Wisconsin 53705, ${ }^{4}$ Department of Medical Physics, \\ University of Wisconsin-Madison, Madison, Madison, Wisconsin 53705, 5Department of Biomedical Engineering, University of Wisconsin-Madison, \\ Madison, Wisconsin, 53706, ${ }^{6}$ Department of Radiology, University of Wisconsin-Madison, Madison, Wisconsin, 53792, and ${ }^{7}$ Department of Psychology, \\ University of Wisconsin-Madison, Madison, Wisconsin 53706
}

Dopamine (DA) levels in the striatum are increased by many therapeutic drugs, such as methylphenidate (MPH), which also alters behavioral and cognitive functions thought to be controlled by the PFC dose-dependently. We linked DA changes and functional connectivity (FC) using simultaneous $\left[{ }^{18} \mathrm{~F}\right]$ fallypride PET and resting-state fMRI in awake male rhesus monkeys after oral administration of various doses of $\mathrm{MPH}$. We found a negative correlation between $\left[{ }^{18} \mathrm{~F}\right]$ fallypride nondisplaceable binding potential $\left(\mathrm{BP}_{\mathrm{ND}}\right)$ and $\mathrm{MPH}$ dose in the head of the caudate (hCd), demonstrating increased extracellular DA resulting from MPH administration. The decreased $\mathrm{BP}_{\mathrm{ND}} \mathrm{Was}$ negatively correlated with FC between the hCd and the PFC. Subsequent voxelwise analyses revealed negative correlations with FC between the hCd and the dorsolateral PFC, hippocampus, and precuneus. These results, showing that MPH-induced changes in DA levels in the hCd predict resting-state FC, shed light on a mechanism by which changes in striatal DA could influence function in the PFC.

Key words: dopamine; fallypride; methylphenidate; PET/MR

Significance Statement

Dopamine transmission is thought to play an essential role in shaping large scale-neural networks that underlie cognitive functions. It is the target of therapeutic drugs, such as methylphenidate (Ritalin), which blocks the dopamine transporter, thereby increasing extracellular dopamine levels. Methylphenidate is used extensively to treat attention deficit hyperactivity disorder, even though its effects on cognitive functions and their underlying neural mechanisms are not well understood. To date, little is known about the link between changes in dopamine levels and changes in functional brain organization. Using simultaneous PET/MR imaging, we show that methylphenidate-induced changes in endogenous dopamine levels in the head of the caudate predict changes in resting-state functional connectivity between this structure and the prefrontal cortex, precuneus, and hippocampus.

\section{Introduction}

Methylphenidate (MPH; e.g., Ritalin) is one of the most common psychostimulants prescribed to treat children with attention def- icit hyperactivity disorder (ADHD) (Arnsten, 2006). It binds to the dopamine (DA) transporter (DAT) and norepinephrine (NE) transporter and blocks neurotransmitter reuptake (Krause, 2008; 


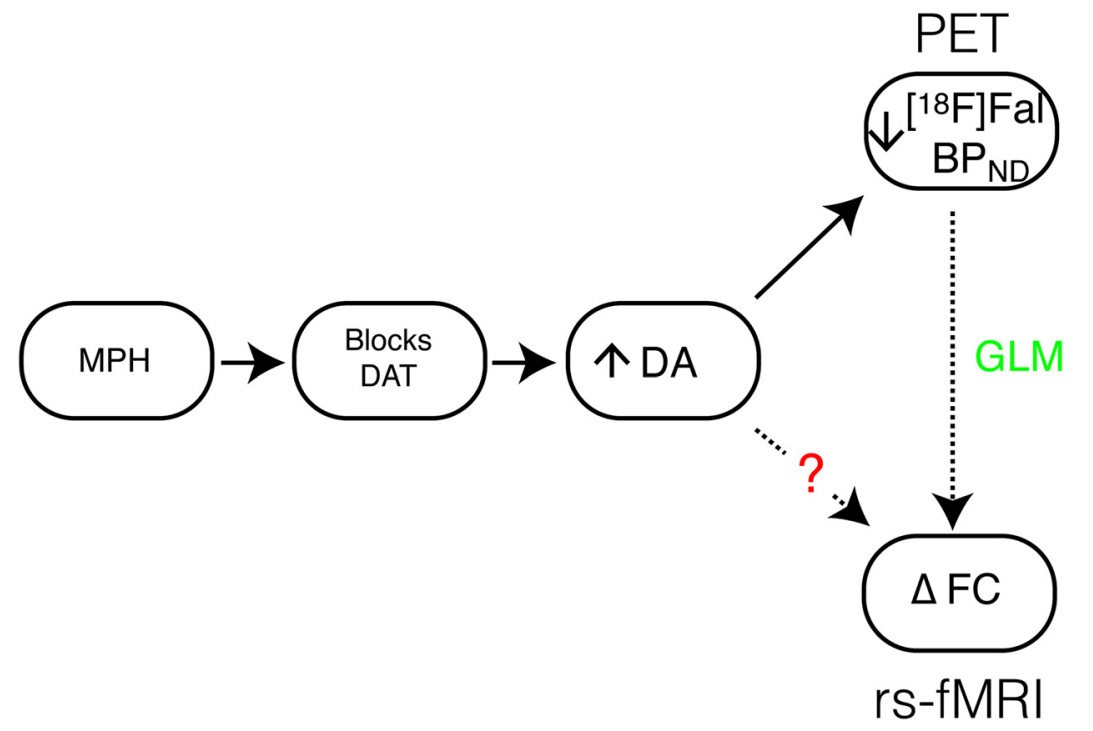

Figure 1. Schematic representation of the study. MPH blocks DAT, which causes extracellular levels of DA to increase. Red "?," Goal of the study: to link changes in extracellular levels of DA to changes in $F C(\triangle F C)$. Extracellular levels of DA were inferred by measuring changes in $\mathrm{BP}_{\mathrm{ND}}$ of $\left[{ }^{18} \mathrm{~F}\right]$ fallypride brought about by different doses of $\mathrm{MPH}$ in specific brain regions. Changes in $\mathrm{FC}$ were measured with rsfMRI. The link between $B P_{N D}$ and MPH was established using a GLM.

Hannestad et al., 2010), thereby increasing their extracellular levels (Volkow et al., 2002), which alters behavioral/cognitive functions thought to be under the control of the PFC dosedependently (Sprague and Sleator, 1977; Arnsten, 2011; Rajala et al., 2012). The pattern of effects is described by an inverted-U dose-response function (Sprague and Sleator, 1977; Gamo et al., 2010; Rajala et al., 2012). Prior studies at the systems-wide level have examined the effects of MPH on the networks that connect different brain regions, but questions remain about the relationship between changes to the organization of the brain's functional networks and changes to extracellular levels of DA brought about by the administration of oral doses of the drug (Zimmer, 2009).

Changes in extracellular concentration of DA can be measured with PET exploiting the sensitivity of select PET radioligands to endogenous neurotransmitter competition for receptor binding. For example, the binding of the $\mathrm{D}_{2} / \mathrm{D}_{3} \mathrm{DA}$ receptor antagonist $\left[{ }^{18} \mathrm{~F}\right]$ fallypride (Mukherjee et al., 1997) can be measurably reduced following treatment with D-amphetamine or cocaine (Schlaepfer et al., 1997) as a result of increased synaptic DA competition for the binding sites. Similar changes in PET ligand binding have been reported with therapeutic doses of MPH (Volkow et al., 2002; del Campo et al., 2013), which binds to DAT, yielding significant increases in extracellular DA in the striatum, where DAT availability is highest (Ouchi et al., 1999). We chose $\left[{ }^{18} \mathrm{~F}\right]$ fallypride because of its high affinity for the $\mathrm{DA} \mathrm{D}_{2} / \mathrm{D}_{3}$ receptor, which allows for the measurement of changes in endogenous DA levels in areas where receptor density is lower, such as the cerebral cortex (Christian et al., 2000). Microdialysis measurements in monkeys using doses of MPH equivalent to those used to treat humans (Doerge et al., 2000) yielded similar results. However, increased levels of DA were observed in the PFC only at much higher, cognitively impairing doses (Kodama et al., 2017). Thus, the question remains as to how increased levels of DA in the

Correspondence should be addressed to Luis C. Populin at Ipopulin@wisc.edu.

https://doi.org/10.1523/JNEUROSCI.2513-18.2018

Copyright $\odot 2019$ the authors $\quad 0270-6474 / 19 / 391437-09 \$ 15.00 / 0$ striatum resulting from therapeutic doses of MPH could lead to changes in PFC function.

Changes in the functional organization of the brain measured with fMRI in humans in response to MPH have shown alterations in different brain networks, particularly the default mode and frontostriatal networks. Changes in functional connectivity (FC) in frontostriatal circuitry following administration of MPH have been mixed, however, with some studies reporting increases in frontostriatal connectivity (Nagano-Saito et al., 2008; Kelly et al., 2009; Rubia et al., 2009), and others reporting decreases (Farr et al., 2014; Mueller et al., 2014; Hong et al., 2015), which may be explained by the fact that most studies used a single dose of the drug and different experimental conditions. Task activation data also show increased activation in frontal regions and basal ganglia following MPH administration (Peterson et al., 2009; Tomasi et al., 2011).

In this study, we bridged the gap between neurochemistry and functional organization by simultaneously measuring changes in extracellular DA using PET imaging of the $\mathrm{D}_{2} / \mathrm{D}_{3}$-specific neuroligand $\left[{ }^{18} \mathrm{~F}\right]$ fallypride, and FC with resting-state fMRI (rsfMRI) at various doses of MPH in awake rhesus monkeys (Fig. 1). Our results identify, for the first time, an MPH dose-dependent link between $\left[{ }^{18} \mathrm{~F}\right]$ fallypride nondisplaceable binding potential $\left(\mathrm{BP}_{\mathrm{ND}}\right)$ in the head of the caudate $(\mathrm{hCd})$ and FC between this area, used as a seed, and prefrontal, hippocampal, and motor regions, which are involved in attention, memory, and motor functions affected by MPH.

\section{Materials and Methods}

Animals and procedures. Three male rhesus monkeys (Macaca mulatta; 10-12 years of age, $8-15 \mathrm{~kg}$ in weight), purchased from the Wisconsin National Primate Research Center, were used. The animals were individually housed in the same room and received identical husbandry and veterinary care; no other monkeys were tested. All experimental procedures were approved by the University of Wisconsin Institutional Animal and Care and Use Committee and were in accord with the National Institutes of Health Guide for the care and use of laboratory animals.

Behavioral training. All training and behavioral procedures were based on positive reinforcement, which consisted of pieces of fruit and/or liquid. The animals were first trained to enter a custom-built primate chair, then trained to accept being placed in the sphinx position using a custom-feature of the chair that allowed for gradual forward tilting (15 degree steps). When the full sphinx position was achieved, the animals inside the chair were placed on the bed of a mock scanner for acclimation and exposure to the scanner's noise. Subsequently, they underwent a surgical procedure to attach an MR-compatible head post. Briefly, under sterile conditions, the top of the head of the monkeys was prepared for surgery. An incision was made rostrocaudally, at the center the head, the soft tissues retracted, the bone exposed, and 14 ceramic screws (Thomas Recording, Type SI06) were inserted in the skull, and a custom head post was attached to the screws with Justi Cold-cure ortho resin (American Tooth Industries). The post was placed caudally on the skull, centered approximately at interaural level, to minimize interference with MR and PET signals from the frontal part of the brain. The post was used with a coupler to restrain the subject's head using a feature of the MR-compatible primate chair. After the surgery, a period of 8 weeks was allowed to pass before restraining the subjects' heads to ensure that the implant area had healed 


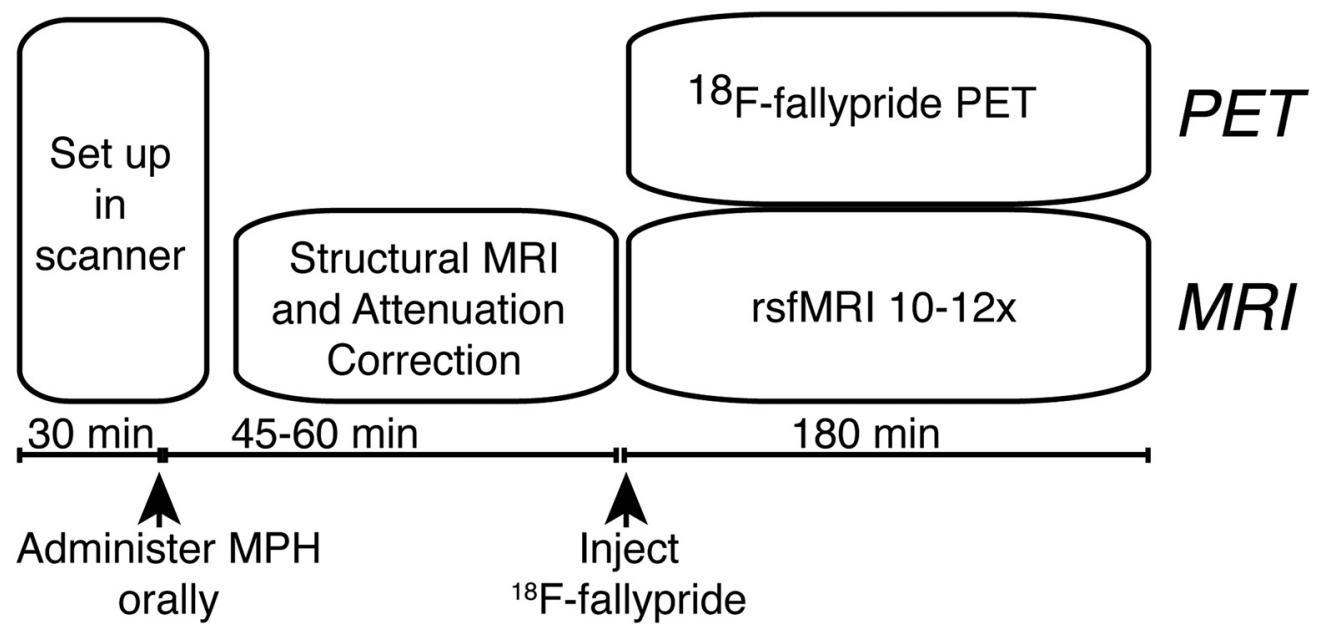

Figure 2. Experiment timeline. Upon arrival to the scanner, the first 30 min were used to set up the eye tracking and reward delivery equipment and position the subject on the scanner bed. Once the subject was ready, MPH was administered orally, just before moving the subject inside the bore of the magnet. The camera and display monitor were set up, and then MRI scanning was started. Structural MRI attenuation correction and fieldmap correction scans were collected. Forty-five to $60 \mathrm{~min}$ after MPH administration, MRI acquisition was stopped and the PET scan started $1 \mathrm{~min}$ before a bolus of $\left[{ }^{18} \mathrm{~F}\right]$ fallypride was given via a catheter line from behind the scanner. Subsequently, a series of $10-1210 \mathrm{~min}$ rsfMRI scans were acquired simultaneously with the PET scan for a total scan time of $180 \mathrm{~min}$.

properly, and that bone had grown around the ceramic screws. During this period, the animals continued to be placed in the primate chair and were trained on tasks that did not require restraining the head. Emphasis was placed on training the animals to move as little as possible.

Behavioral setup for scanning experiments. In addition, the animals were also trained to enter a custom tabletop restraining device, and to accept the insertion of a removable 20 GA catheter, 0.25 or 2 inch length (Surflash IV, Terumo) into the cephalic vein of the leg. Once inserted, the catheter was secured in place with tape and vet wrap. The monkey was then guided to the primate chair for transport to the scanning facility. This was an essential step for the administration of the PET tracer, which was also accomplished with positive reinforcement.

Upon arriving to the scanner facility, the monkey was placed in the sphinx position and onto the bed in front of the scanner, where its head was restrained with a custom head-post holder, and a 3 inch receive-only MR loop coil was placed above the subject's head for imaging. A water spout was placed in front of the subject's lips to provide rewards during the preparation. In addition, the catheter was exposed and connected to a line filled with heparinized saline, and secured in place. The animal was inserted into the bore of the scanner tail first. A video-based eye tracker (Eyelink 1000Plus, SR Research, RRID:SCR_009602) was placed $150 \mathrm{~cm}$ away from the head, immediately in front of an MR-compatible computer screen used to present a dot for the monkey to fixate during data acquisition.

Experimental timeline. After administering the randomly selected dose of MPH on the scanner bed, the setup of the subject and equipment was completed (5-10 min). A series of structural scans and a fieldmap for distortion correction were acquired $(\sim 20 \mathrm{~min})$ before starting the 10 min rsfMRI scans. Before each rsfMRI scan, the signals from the eye tracker

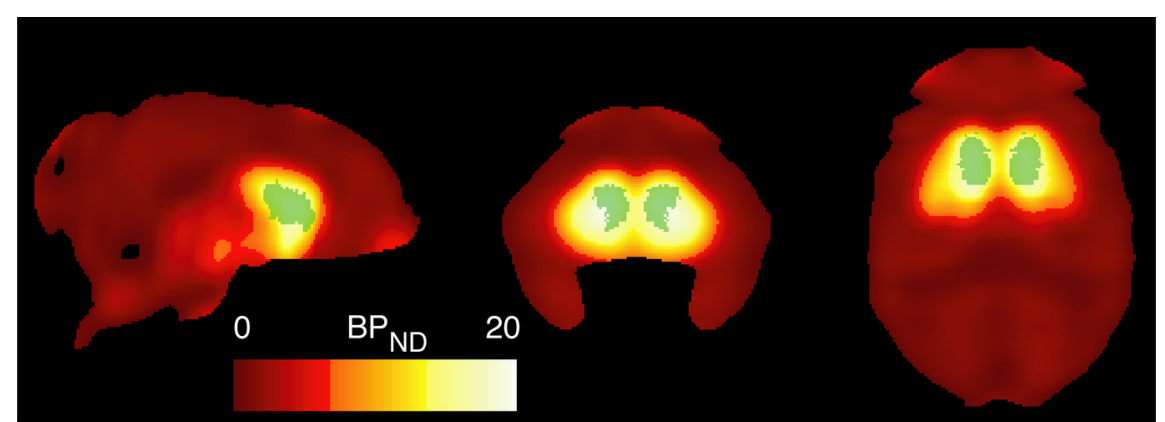

Figure 3. PET imaging of $D_{2} / D_{3}$ receptor availability. $\left[{ }^{18} \mathrm{~F}\right]$ Fallypride binding map of Subject GR at baseline exhibiting high concentrations of available $D_{2} / D_{3}$ receptors in striatum. Green represents $h C d$. Sagittal, coronal, and axial slices shown at left striatum. Binding is shown on a nonlinear scale to visualize uptake in regions outside of striatum.

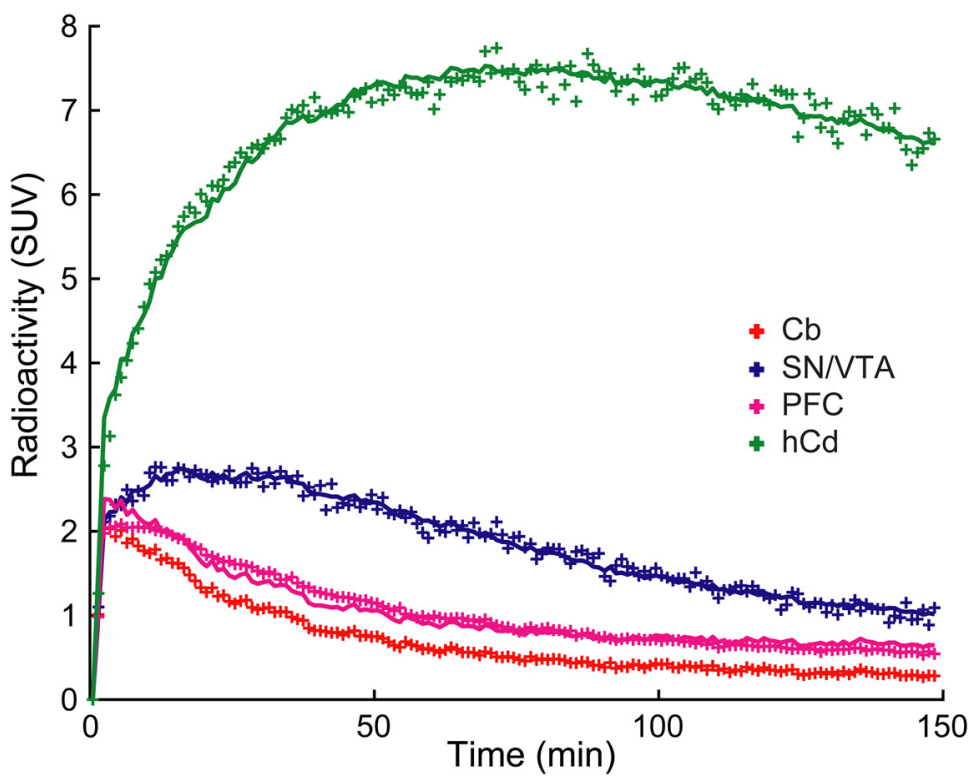

Figure 4. Pharmacokinetic modeling of $\left[{ }^{18} \mathrm{~F}\right]$ fallypride binding. Time-activity curves for ROIs in Subject GR at baseline. +, Individual dynamic measurements. Solid lines indicate simplified reference tissue model fits to data. $y$ axis indicates standardized uptake value (SUV), which was computed as radioactivity concentration/(injected radioactivity/body weight). Cb, Cerebellar reference region. 
Table 1. $[18 \mathrm{~F}]$ Fallypride binding $\left(\mathrm{BP}_{\mathrm{ND}}\right)$ in ROls

\begin{tabular}{|c|c|c|c|c|c|}
\hline$\overline{\mathrm{MPH}}(\mathrm{mg} / \mathrm{kg})$ & Subject & Putamen & $\mathrm{hCd}$ & SN/VTA & PFC \\
\hline \multirow[t]{4}{*}{0.0} & GR & 16.1 & 15.8 & 1.87 & 0.55 \\
\hline & GO & 19.4 & 15.3 & 2.50 & 0.51 \\
\hline & MI & 19.5 & 14.2 & 2.18 & 0.49 \\
\hline & Mean \pm SD & $18.33 \pm 1.93$ & $15.10 \pm 0.82$ & $2.18 \pm 0.32$ & $0.52 \pm 0.03$ \\
\hline \multirow[t]{4}{*}{1.5} & GR & 17.4 & 16.5 & 2.10 & 0.55 \\
\hline & GO & 18.8 & 14.0 & 2.29 & 0.41 \\
\hline & Ml & 20.7 & 14.4 & 2.32 & 0.52 \\
\hline & Mean \pm SD & $18.97 \pm 1.66$ & $14.97 \pm 1.34$ & $2.24 \pm 0.12$ & $0.49 \pm 0.07$ \\
\hline \multirow[t]{4}{*}{3.0} & GR & 15.3 & 14.9 & 1.85 & 0.51 \\
\hline & GO & 18.2 & 13.9 & 2.22 & 0.44 \\
\hline & Ml & 19.4 & 14.1 & 2.17 & 0.54 \\
\hline & Mean \pm SD & $17.63 \pm 2.11$ & $14.30 \pm 0.53$ & $2.08 \pm 0.20$ & $0.49 \pm 0.05$ \\
\hline \multirow[t]{6}{*}{6.0} & GR & 15.4 & 15.0 & 1.82 & 0.44 \\
\hline & G0 & 18.7 & 13.3 & 2.36 & 0.46 \\
\hline & $\mathrm{Ml}$ & 19.4 & 13.5 & 2.28 & 0.50 \\
\hline & Mean \pm SD & $17.83 \pm 2.14$ & $13.93 \pm 0.93$ & $2.15 \pm 0.29$ & $0.47 \pm 0.93$ \\
\hline & Dose dependence ${ }^{a}$ & $-0.73 \pm 0.47$ & $-1.37 \pm 0.37$ & $-0.46 \pm 0.65$ & $-1.48 \pm 0.98$ \\
\hline & $p$ uncorrected $^{b}$ & 0.149 & $0.005^{*}$ & 0.488 & 0.162 \\
\hline
\end{tabular}

${ }^{a}$ Fractional change in $\left[{ }^{18} \mathrm{~F}\right]$ fallypride binding potential relative to baseline versus $\mathrm{MPH}$ dose $(\% / \mathrm{mg} / \mathrm{kg} \pm \mathrm{SE}$ ) from mixed-effects GLM.

${ }^{b}$ Two-tailed $t$ test.

${ }^{*} p<0.05$, corrected for multiple comparisons.

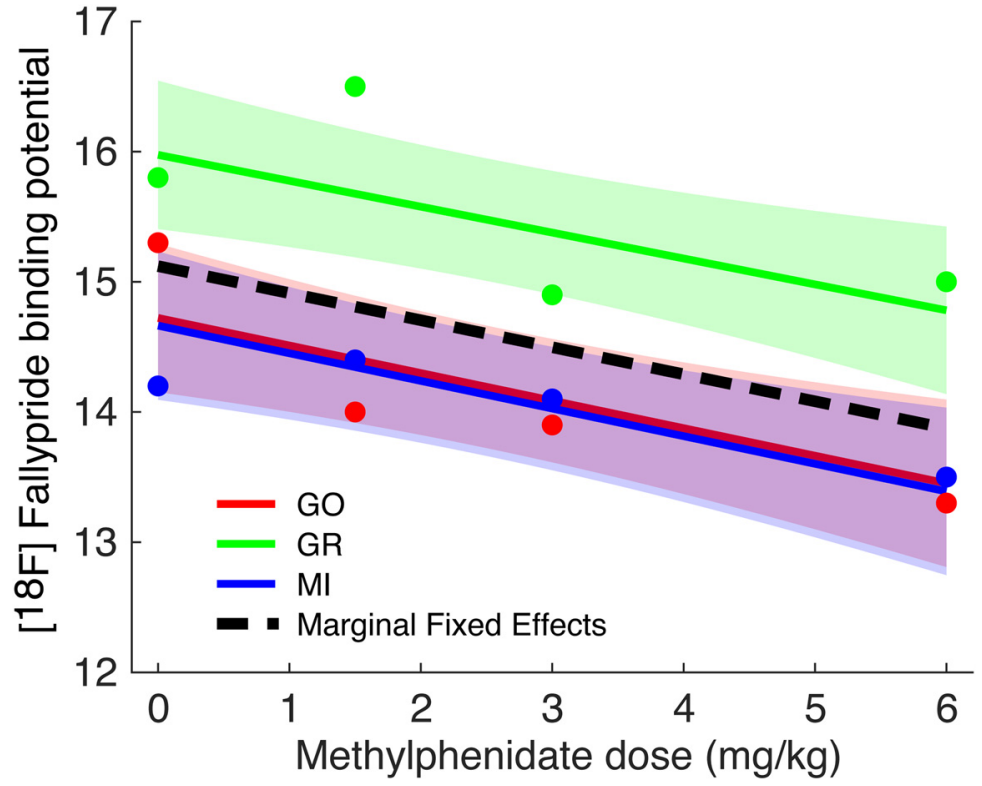

Figure 5. $\quad\left[{ }^{18} \mathrm{~F}\right]$ fallypride binding potentials from model fits to head of caudate time-activity curves, plotted as a function of administered MPH dose. This shows a significant dose dependence, which is expected to result from competition with increasing concentrations of extracellular DA (slope $=-0.21$; fractional change $-1.37 \%$ per milligrams per kilogram, $p=0.0045$ ). A linear mixed-effects model describes the relationship between $\mathrm{BP}_{\mathrm{ND}}$ and $\mathrm{MPH}$ dose, where the intercept and slope are fixed effects and subjects were treated as random effects to model individual differences (intercepts and slopes). The conditional predicted responses and $95 \%$ point-wise Cls are shown for 3 individual subjects (solid color). Dotted line indicates the marginal fixed effect.

were calibrated; during each 10 min run, the subject was presented with a central fixation dot using Experiment Builder (SR Research), fixation of which was not enforced. No rewards were administered during the resting-state scans. Approximately 45-60 min after oral administration of MPH, the tracer was injected through the catheter extension tube, which was positioned to the rear of the scanner during setup. A series of 10-12 10 min rsfMRI runs were collected for $3 \mathrm{~h}$ after tracer injection, simultaneous with the $3 \mathrm{~h}$ PET scan (Fig. 2).

Drug delivery and dosing. MPH hydrochloride (Sigma-Aldrich) was administered orally, dissolved in $0.5 \mathrm{ml}$ grape-cranberry juice after the subject was fully set up on the scanner bed, but before it was moved into the bore of the magnet. The doses used in this study $(1.5,3$, and $6 \mathrm{mg} / \mathrm{kg})$ were used previously (Rajala et al., 2012) and were chosen based on the work of Doerge et al. (2000) who determined that an acute oral dose of $3 \mathrm{mg} / \mathrm{kg} \mathrm{MPH}$ in the monkey resulted in plasma levels similar to those used therapeutically in humans treated for ADHD. Drug dosing was calculated in milligrams per kilogram based on the animals weight the day of the experimental session. Vehicle (juice only) was administered in a similar manner as a control. Each subject underwent four scanning sessions, one with each of the three doses plus vehicle.

PET imaging. $\left[{ }^{18} \mathrm{~F}\right]$ Fallypride was synthesized as described previously (Mukherjee et al., 1995); $3 \mathrm{mCi}$ was injected in an intravenous bolus, and data were acquired for $180 \mathrm{~min}$ (Fig. 2). Images were reconstructed by ordered subset expectation maximization to 1 min frames with corrections for attenuation and scatter using $511 \mathrm{keV}$ attenuation coefficient maps based on a combination of MR images of the subjects and a coregistered CT image of the housing, MR coil, and other apparatus within the PET FOV.

PET image alignment. PET images were aligned to a rhesus brain template as follows (Jenkinson et al., 2002; Moirano et al., 2018). To better visualize whole brain, sum images $0-15$ min after injection of tracer were created. These $0-15$ min images were aligned by 6 degrees of freedom (shifts and rotations) to the template, and the resulting transformation matrices were applied to the dynamic, 0-180 min, images. The dynamic images were motion corrected with respect to the image frame at $15 \mathrm{~min}$ using the FMRIB Software Library's (FSL) mcflirt. The $0-15$ min sum images were again created and aligned within subject as follows. For each subject, images were first aligned by 6 degrees of freedom to the template, averaged, and aligned to the average. The average was again aligned to the template by 9 degrees of freedom (shifts, rotations, and zooms). The resulting transformation matrices were concatenated and applied to the dynamic images. This yielded motion-corrected images aligned within subject to the template space. 
Pharmacokinetic modeling. Time activity curves were calculated for five ROIs based on the Paxinos rhesus atlas: hCd, putamen, PFC, substantia nigra/ventral tegmental area (SN/VTA), and a cerebellar reference region (Paxinos et al., 2009; Moirano et al., 2018). Binding potentials with respect to nondisplaceable uptake $\left(\mathrm{BP}_{\mathrm{ND}}\right)$ were estimated using the simplified reference tissue model (Lammertsma and Hume, 1996; Innis et al., 2007; Vernaleken et al., 2011). The binding potentials' relationship to MPH dose was examined by fitting the following mixed-effects GLM as follows:

$$
B P_{j k}=\beta_{0}+a_{j}+\left(\beta_{1}+b_{j}\right) \mathrm{MPH}_{k}+e_{j k}
$$

where $\beta_{0}$ and $\beta_{1}$ are the intercept and slope fixed effects for the MPH dose of the kth (1 $\leq k \leq 4)$ observation, $a_{j}$ and $b_{j}$ are the random effects specific to subject $j(1 \leq j \leq 3)$, $B P_{j k}$ is the subject-specific binding potential response, and $e_{j k}$ is the random error term (Gelman and Hill, 2007). Mixed-effects models were fit using the MATLAB (RRID: SCR_001622) Statistics and Machine Learning Toolbox (fitlmematrix).

fMRI analysis. All fMRI data analyses were performed using the AFNI software package (Cox, 1996) (RRID:SCR_005927) unless otherwise indicated. Specific programs used are provided in parentheses. T1-weighted structural MRI scans were aligned to a template brain (Calabrese et al., 2015) using a 12parameter affine transformation (AFNI's @auto_tlrc script). Functional MRI echo-planar time series were first corrected for B0-field distortions using an acquired B0-field map and FSL's fugue. Data were then corrected for motion using rigid-body registration (3dvolreg) and corrected for slice-timing differences (3dTshift). Time points with a volume-tovolume motion (sum squared difference of the 6 realignment parameters) exceeding $0.2 \mathrm{~mm}$, as well as the subsequent 10 TRs, were censored and not used in the subsequent analyses. On average, $7.6 \%$ of volumes were censored (median $=5.1 \%$ ). The corrected EPI data were then aligned to the T1-weighted structural MRI using a 12-parameter affine transformation (align_epi_anat.py). This transformation was combined with the $\mathrm{T} 1$ to template transformation and applied to the EPI data in original space to warp the EPI data into template space with only one resampling step. The average signals in the white matter and CSF, as well as their temporal derivatives, were then regressed from the data (3dTproject). Finally, the data were spatially smoothed by $1 \mathrm{~mm}$ within a mask of the brain.

First, we examined the FC between the hCd, the region where PET $\left[{ }^{18} \mathrm{~F}\right]$ fallypride $\mathrm{BP}_{\mathrm{ND}}$ was most strongly and significantly associated with $\mathrm{MPH}$ dose, and the entire PFC gray matter (on average). The hCd was defined using a digitized version of the Paxinos atlas (Paxinos et al., 2009; Moirano et al., 2018). The template brain was segmented into gray matter, white matter, and CSF using FSL's fast. A PFC mask was created by taking all gray matter voxels anterior to the genu of the corpus callosum and dilating this mask by 1 voxel $(2 \mathrm{~mm})$ into the brain to account for the lower-resolution EPI and applied spatial smoothing. The goal of this analysis was to address the hypothesized effects of increased extracellular DA levels resulting from MPH on the frontal lobe, in general, in the control of cognitive functions. The following GLM was fit:

$$
F C_{j k}=\beta_{0}+a_{j}+\left(\beta_{1}+b_{j}\right) B P_{j k}+e_{j k}
$$

where $\beta_{0}$ and $\beta_{1}$ are the intercept and slope fixed effects for the fallypride binding potential $\mathrm{BP}$ of the $\mathrm{k}^{\text {th }}$ observation, $a_{j}$ and $b_{j}$ are the random effects specific to Subject $j, F C_{j k}$ is the subject specific FC response, and $e_{j k}$ is the random error term. In this case, $(1 \leq k$ $\left.\leq K_{j}\right)$, where $K_{j}=4 \mathrm{MPH}$ doses $\times$ number of runs at each dose $\left(K_{G O}=\right.$ $50, K_{G R}=48$, and $K_{M I}=49$ ).

Voxelwise FC maps were generated by computing the average signal intensity time course in the caudate head and then computing the temporal correlation with the signal intensity time course in all other brain voxels (AFNI's 3 dDeconvolve). Areas that showed significant association between $\left[{ }^{18} \mathrm{~F}\right]$ fallypride BP and FC were then determined using a linear mixed-effects analysis ( $3 d L M E)$ across all subjects and imaging runs, with $\left[{ }^{18} \mathrm{~F}\right]$ fallypride $\mathrm{BP}$ as a covariate. The 3 subjects were treated as random effects in the mixed-effects model. Voxelwise FC maps were corrected for multiple comparisons using a cluster-based approach and an individual-voxel $p$ value threshold of 0.001 . This cluster-based approach estimates the spatial autocorrelation function (as the sum of a Gaussian and exponential) of the following form:

$$
a \exp \left\{-\frac{r^{2}}{2 b^{2}}\right\}+(1-a) \exp \left\{-\frac{r}{c}\right\}
$$

with $a=0.82, b=2.07$, and $c=8.41$ (using AFNI's $3 d F W H M x$ ), and then runs a Monte Carlo simulation (3dClustSim) to determine the likelihood of getting clusters of a certain size (Cox et al., 2017). 

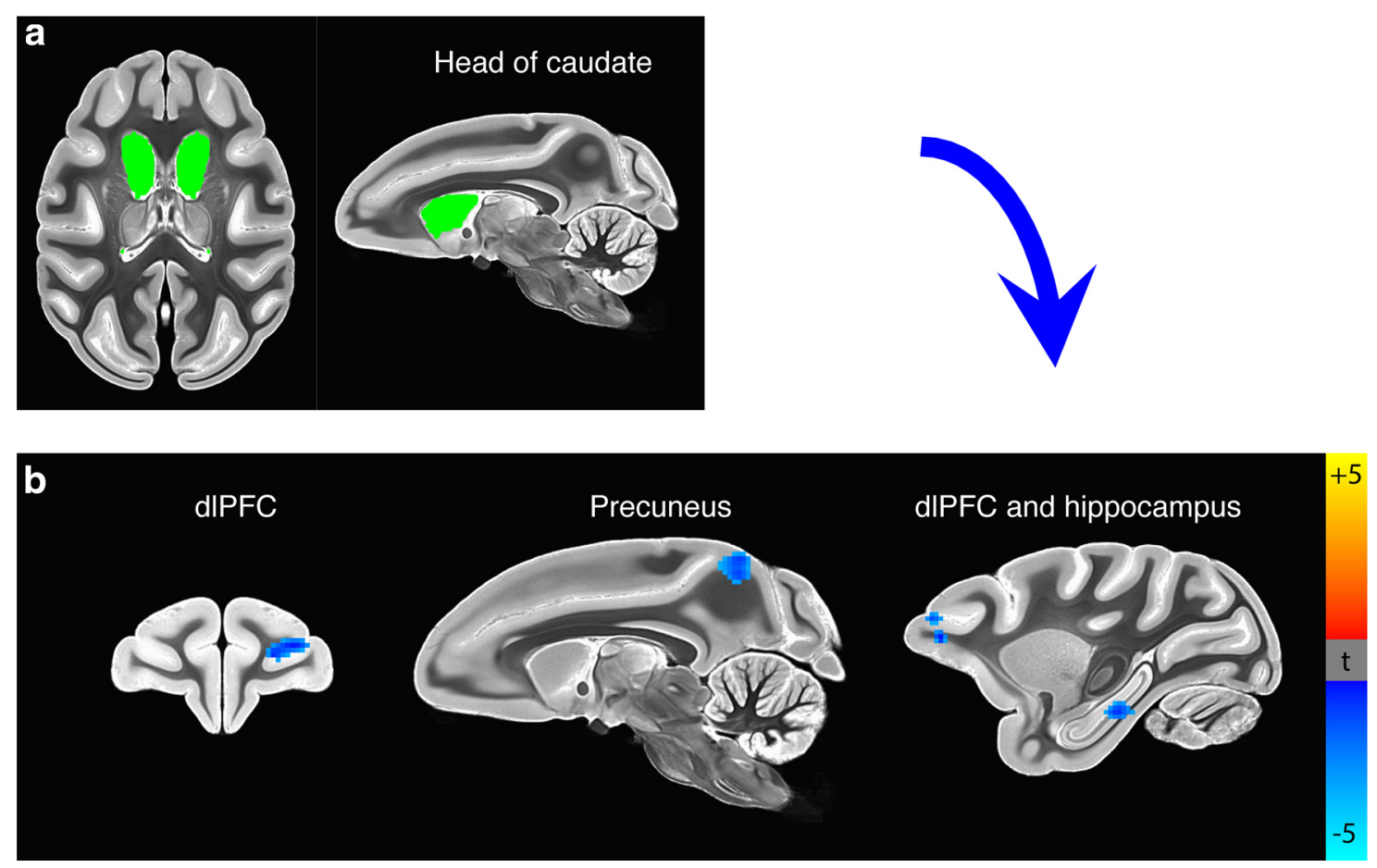

Figure 7. $\quad \boldsymbol{a}, \mathrm{ROI}$ (green) in the hCd that was used as a seed for computing voxelwise FC. $\boldsymbol{b}$, Colored regions represent areas where hCd FC is significantly (negatively) correlated with $\left[{ }^{18} \mathrm{~F}\right] \mathrm{falllyp}$ ride binding potential ( $\left.\mathrm{BP}_{\mathrm{ND}}\right)$ in $\mathrm{hCd}$. There is a significant negative correlation between $\left[{ }^{18} \mathrm{~F}\right] \mathrm{fallypride} \mathrm{BP}_{\mathrm{ND}}$ and the connectivity between $\mathrm{hCd}$ and dIPFC $(p=0.0014)$, hippocampus $(p=0.0003)$, and precuneus ( $p=0.0032$ ). All $p$ values are corrected for multiple comparisons.

\section{Results}

Data were collected from 3 adult male rhesus monkeys (Subjects $\mathrm{GO}, \mathrm{GR}$, and $\mathrm{MI}$ ) trained to sit quietly in the bore of the PET/MR scanner for up to $5 \mathrm{~h}$ to be imaged while at rest. Scans were performed following oral administration of MPH (Fig. 2) at four dose levels $(0,1.5,3.0$, and $6.0 \mathrm{mg} / \mathrm{kg})$.

\section{PET}

Our first goal was to obtain an index of changes in endogenous DA concentration in striatal and cortical regions of the brain. $\mathrm{BP}_{\mathrm{ND}}$ of the highly selective $\mathrm{D}_{2} / \mathrm{D}_{3}$ antagonist $\left[{ }^{18} \mathrm{~F}\right]$ fallypride was measured by dynamic PET imaging. Elevated levels of $D_{2} / D_{3}$ specific binding were readily observed in the striatum (Fig. 3 ). Estimates of $\mathrm{BP}_{\mathrm{ND}}$ were obtained from the time course of radiotracer concentrations in anatomically identified ROIs using the simplified reference tissue model (Fig. 4) (Lammertsma and Hume, 1996; Vernaleken et al., 2011) and the cerebellum as the reference region of negligible specific binding. This yielded a $\mathrm{BP}_{\mathrm{ND}}$ for each of the 3 subjects at the four dose levels of MPH, given orally $\sim 1 \mathrm{~h}$ before the administration of $\left[{ }^{18} \mathrm{~F}\right]$ fallypride (Fig. 2; Table 1). $\mathrm{BP}_{\mathrm{ND}}$ was found to correlate negatively with $\mathrm{MPH}$ dose in the hCd, where $\mathrm{BP}_{\mathrm{ND}}$ decreased by $1.37 \%(p=0.005)$ per milligrams per kilogram of $\mathrm{MPH}$, suggesting increased extracellular DA competition (to reduce $\left[{ }^{18} \mathrm{~F}\right]$ fallypride binding) resulting from the administration of MPH (Fig. 5).

\section{fMRI}

Because MPH affects cognitive functions thought to be under the control of the PFC, our next goal was to determine whether the significant decrease in $\left[{ }^{18} \mathrm{~F}\right]$ fallypride $\mathrm{BP}_{\mathrm{ND}}$ observed in the hCd, as measured by PET (Fig. 5; Table 1), was correlated with the FC between the hCd and the PFC. Thus, we first examined the influence of MPH on the FC between the hCd and PFC gray matter as a whole. The data were fit with a mixed-effects model (Eq. 2). The analysis showed that the hCd-PFC FC was significantly (negatively) correlated with $\left[{ }^{18} \mathrm{~F}\right]$ fallypride $\mathrm{BP}_{\mathrm{ND}}$ in the hCd $(p=0.019$, Fig. 6) for the multiple MPH doses. That is, lower $\left[{ }^{18} \mathrm{~F}\right]$ fallypride $\mathrm{BP}_{\mathrm{ND}}$, indicating increased competition from endogenous DA, was associated with higher hCd-PFC FC.

Subsequently, we focused on the association between $\left[{ }^{18} \mathrm{~F}\right]$ fallypride $\mathrm{BP}_{\mathrm{ND}}$ and hCd $\mathrm{FC}$ on a voxelwise basis across the entire brain, with corrections for multiple comparisons. This analysis revealed that hCd $\left[{ }^{18} \mathrm{~F}\right]$ fallypride $\mathrm{BP}_{\mathrm{ND}}$ was significantly (negatively) associated with the FC between the hCd and three clusters in the brain (Fig. 7$)$ : the dorsolateral PFC (dlPFC) $(p=$ $0.0014)$, the hippocampus $(p=0.0003)$, and the precuneus area $(p=0.0032)$.

Last, the results of the FC analyses for the three individual regions identified with the voxelwise approach show that the effects are not driven by outliers from a single subject (Fig. 8). The linear regression lines in these plots were computed separately for each set; that is, they are not the output of the voxelwise mixedeffects model and are considered descriptive, not inferential. The statistical significance of these effects is as indicated above by the voxelwise $p$ values, corrected for multiple comparisons.

\section{Discussion}

Central to the quest for understanding the mechanisms underlying the effects of therapeutically relevant doses of MPH on the function of the nervous system has been to determine how changes in cognitive functions thought to be under the control of the PFC result from increases in dopaminergic function in the striatum (Volkow et al., 2002; Kodama et al., 2017), where DAT expression is highest (Ouchi et al., 1999). This study sheds much needed light on this issue and points to a potential, biologically viable mechanism. 

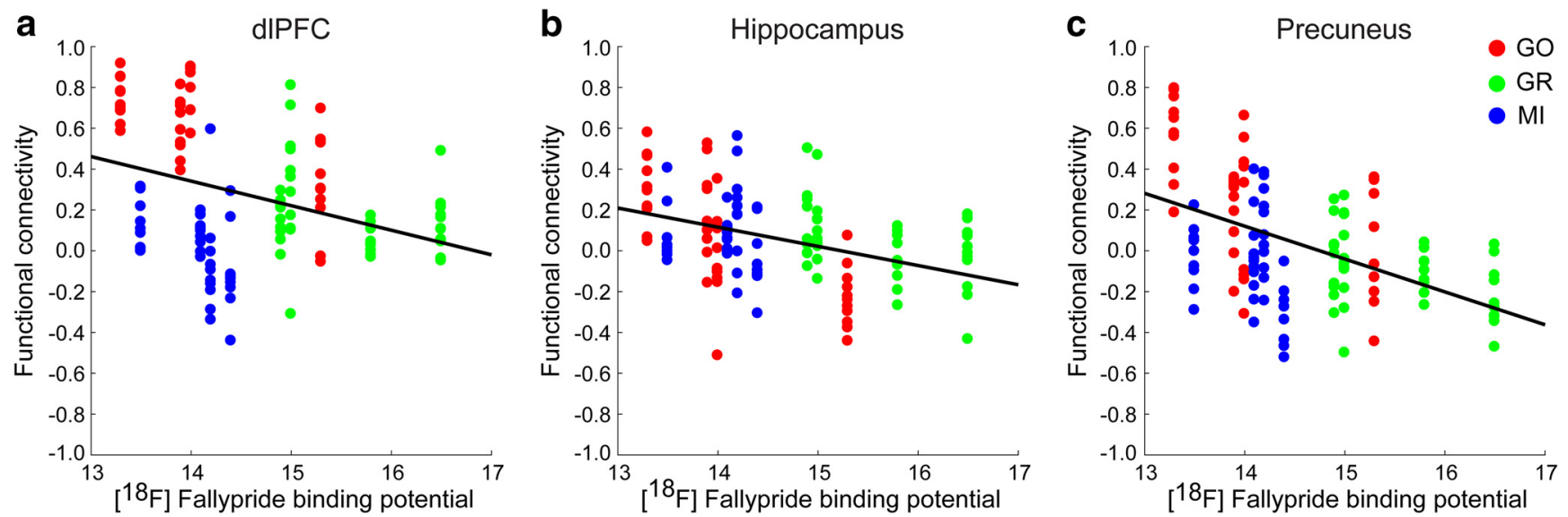

Figure 8. Plot showing individual runs of $\mathrm{FC}$ versus $\left[{ }^{18} \mathrm{~F}\right]$ fallypride binding potential (BP) in hCd for the three significant clusters from Figure 7 , computed using $\mathrm{h} C \mathrm{~d}$ as a seed region and $(\boldsymbol{a})$ dIPFC (slope: -0.12023 ; intercept: 2.025), (b) hippocampus (slope: -0.094 ; intercept: 1.430), and (c) precuneus (slope: -0.161 ; intercept: 2.374 ). Each point represents FC computed from one 10 min rsfMRI run. Colors of the points represent each of the 3 subjects. The linear regression lines in these plots were computed separately for each set and are considered descriptive, not inferential.

The data show that increasing doses of MPH led to decreasing $\left[{ }^{18} \mathrm{~F}\right]$ fallypride $\mathrm{BP}_{\mathrm{ND}}$, indicative of increasing levels of extracellular DA competing for $\mathrm{D}_{2} / \mathrm{D}_{3} \mathrm{DA}$ receptor binding sites, particularly in the hCd nucleus. These decreases in $\mathrm{BP}_{\mathrm{ND}}$ in the hCd are negatively related to the FC of this structure to the entire frontal lobe (Fig. 6). Subsequent voxelwise analyses revealed that decreases in $\mathrm{BP}_{\mathrm{ND}}$ in the hCd are negatively related to the dlPFC, the hippocampus, and an area in the precuneus (Fig. 5). Thus, increasing levels of extracellular DA in the hCd are associated with increased connectivity of the hCd to these areas.

The dlPFC is a key component of frontostriatal circuitry; thus, increased hCd-dlPFC connectivity may be a mechanism by which $\mathrm{MPH}$, acting primarily on the striatum, affects prefrontal cortical activity thought to underlie improvements in cognitive performance resulting from the administration of oral doses of $\mathrm{MPH}$ (Grace et al., 2007; Krugel et al., 2009). More specifically, the dlPFC is a key component of the attention network, involved in sustained attention. Increased hCd-dlPFC connectivity may therefore be a mechanism for the observed improvement in attention resulting from $\mathrm{MPH}$.

$\left[{ }^{18} \mathrm{~F}\right]$ Fallypride $\mathrm{BP}_{\mathrm{ND}}$ was also significantly correlated with the connectivity between hCd and the most rostral region of the precuneus, an area thought to be involved in sensory motor function because it is functionally connected to the superior parietal cortex, paracentral lobule, and motor cortex (Margulies et al., 2009). Thus, increased connectivity of the hCd to this area may be a mechanism by which MPH reduces hyperactivity.

Last, the connectivity between the caudate and hippocampus has previously been shown to be associated with DA function (Farr et al., 2014). Our findings are consistent with this earlier study that also showed increased caudate-hippocampus FC following the administration of a single dose of MPH. Due to the central role of the hippocampus in memory, it is possible that this connection is a mechanism by which $\mathrm{MPH}$ influences memory function.

At the neuronal circuit level, these increases in FC could result from improvements in signal-to-noise ratio produced by increased levels of DA in the hCd, as demonstrated by the effects of iontophoretic application of DA in the immediate vicinity of single units recorded in the striatum of behaving monkeys (Rolls et al., 1984) and rats (Kiyatkin and Rebec, 1996). High-frequency broadband activity may serve as a proxy for local multiunit activity (Nir et al., 2008), which also covaries with spontaneous fluc- tuations in BOLD signals (Mantini et al., 2007; Shmuel and Leopold, 2008). DA is thought to reduce background firing rates more than that of the signal, such that information flow in the corticostriatal pathway is maximized (Bamford et al., 2004; Nagano-Saito et al., 2008; Bubl et al., 2015). To the degree that $\mathrm{MPH}$ further augments an increase in striatal signal to noise, the temporal correlation with functionally connected areas would also be expected to increase, consistent with our observations. In addition, it must be noted that MPH may also affect cortical function by other mechanisms, such as norepinephrine receptors (Arnsten, 2007), which was not studied here.

Several factors were essential for obtaining the present results. First, to directly relate the PET and fMRI measurements, the subjects needed to be imaged in the same physiological state. This was accomplished by using a simultaneous PET/MR system. This approach also allowed us to estimate $\left[{ }^{18} \mathrm{~F}\right]$ fallypride $\mathrm{BP}_{\mathrm{ND}}$, a more biologically relevant method to measure changes in extracellular levels of DA than MPH dose alone given that the behavioral effects of the drug can vary considerably between subjects and between days (Rajala et al., 2012, 2015). In addition, FC, despite its robustness at delineating brain networks, fluctuates considerably at time scales of minutes to days, likely reflecting the state of the brain at each moment in time (Allen et al., 2014). Therefore, having simultaneous measurements of changes in extracellular DA and functional brain organization is key to linking these two measures. This approach will make it possible for future work to directly investigate the role of changes in DA levels on cognitive task performance and the underlying changes in brain activation.

Second, we chose an animal model over humans to accommodate the administration of various doses of MPH and multiple PET sessions. The awake rhesus monkey ( $M$. mulatta) was selected because of its similarity to humans in the gross organization of the frontal lobes (Wise, 2008), cortical distribution of dopaminergic terminals (Berger et al., 1991), and functional resting-state networks (Hutchison et al., 2011). The awake state ensured that the results would not be compromised by potential spurious effects of anesthetics on the nervous system (Populin, 2005) and cardiovascular function (Brevard et al., 2003). Third, changes in DA levels brought about by a single dose of MPH may be different from day to day in the same subject, as evidenced by observed behavioral variability with the same dose level (Rajala et al., 2012, 2015); thus, the use of an animal model allowed for 
repeated measures in a within-subjects design. In addition, the administration of several doses was required to capture the pattern of changes occurring with increased dose that could explain the inverted-U profile of MPH dose-response functions seen with behavioral measures (Gamo et al., 2010; Rajala et al., 2012). Finally, the use of research animals allowed for more stringent control of outside factors that could influence these measures.

It is important to note that our measurements of baseline $\left[{ }^{18} \mathrm{~F}\right]$ fallypride binding are in agreement with those reported previously (Christian et al., 2009), and the fractional change in $\left[{ }^{18} \mathrm{~F}\right]$ fallypride $\mathrm{BP}_{\mathrm{ND}}$ versus MPH dose is consistent with that observed in humans (del Campo et al., 2013) after accounting for species differences in MPH pharmacokinetics (Wargin et al., 1983; Doerge et al., 2000; Gill et al., 2012; Soto et al., 2012).

Thus, the present results demonstrate, for the first time, significant MPH-induced increases in extracellular DA levels using PET imaging of $\mathrm{D}_{2} / \mathrm{D}_{3}$ receptor availability (Mach et al., 1997; Gill et al., 2012; Allen et al., 2014) (Fig. 5) in the hCd of the rhesus monkey and, using simultaneous fMRI imaging, directly link these increases in DA to changes in FC between the hCd and prefrontal, hippocampal, and motor regions.

\section{References}

Allen EA, Damaraju E, Plis SM, Erhardt EB, Eichele T, Calhoun VD (2014) Tracking whole-brain connectivity dynamics in the resting state. Cereb Cortex 24:663-676. CrossRef Medline

Arnsten AF (2006) Stimulants: therapeutic actions in ADHD. Neuropsychopharmacology 31:2376-2383. CrossRef Medline

Arnsten AF (2007) Catecholamine and second messenger influences on prefrontal cortical networks of "representational knowledge": a rational bridge between genetics and the symptoms of mental illness. Cereb Cortex 17 [Suppl 1]:i6-i15. CrossRef

Arnsten AF (2011) Catecholamine influences on dorsolateral prefrontal cortical networks. Biol Psychiatry 69:e89-e99. CrossRef Medline

Bamford NS, Zhang H, Schmitz Y, Wu NP, Cepeda C, Levine MS, Schmauss C, Zakharenko SS, Zablow L, Sulzer D (2004) Heterosynaptic dopamine neurotransmission selects sets of corticostriatal terminals. Neuron 42: 653-663. CrossRef Medline

Berger B, Gaspar P, Verney C (1991) Dopaminergic innervation of the cerebral cortex: unexpected differences between rodents and primates. Trends Neurosci 14:21-27. CrossRef Medline

Brevard ME, Duong TQ, King JA, Ferris CF (2003) Changes in MRI signal intensity during hypercapnic challenge under conscious and anesthetized conditions. Magn Reson Imaging 21:995-1001. CrossRef Medline

Bubl E, Dörr M, Riedel A, Ebert D, Philipsen A, Bach M, Tebartz van Elst L (2015) Elevated background noise in adult attention deficit hyperactivity disorder is associated with inattention. PLoS One 10:e0118271. CrossRef Medline

Calabrese E, Badea A, Coe CL, Lubach GR, Shi Y, Styner MA, Johnson GA (2015) A diffusion tensor MRI atlas of the postmortem rhesus macaque brain. Neuroimage 117:408-416. CrossRef Medline

Christian BT, Narayanan TK, Shi B, Mukherjee J (2000) Quantitation of striatal and extrastriatal D-2 dopamine receptors using PET imaging of $\left[{ }^{18} \mathrm{~F}\right]$ fallypride in nonhuman primates. Synapse 38:71-79. CrossRef Medline

Christian BT, Vandehey NT, Fox AS, Murali D, Oakes TR, Converse AK, Nickles RJ, Shelton SE, Davidson RJ, Kalin NH (2009) The distribution of D2/D3 receptor binding in the adolescent rhesus monkey using small animal PET imaging. Neuroimage 44:1334-1344. CrossRef Medline

Cox RW (1996) AFNI: software for analysis and visualization of functional magnetic resonance neuroimages. Comput Biomed Res 29:162-173. CrossRef Medline

Cox RW, Chen G, Glen DR, Reynolds RC, Taylor PA (2017) fMRI clustering and false-positive rates. Proc Natl Acad Sci U S A 114:E3370-E3371. CrossRef Medline

del Campo N, Fryer TD, Hong YT, Smith R, Brichard L, Acosta-Cabronero J, Chamberlain SR, Tait R, Izquierdo D, Regenthal R, Dowson J, Suckling J, Baron JC, Aigbirhio FI, Robbins TW, Sahakian BJ, Müller U (2013) A positron emission tomography study of nigro-striatal dopaminergic mechanisms underlying attention: implications for ADHD and its treatment. Brain 136:3252-3270. CrossRef Medline

Doerge DR, Fogle CM, Paule MG, McCullagh M, Bajic S (2000) Analysis of methylphenidate and its metabolite ritalinic acid in monkey plasma by liquid chromatography/electrospray ionization mass spectrometry. Rapid Commun Mass Spectrom 14:619-623. CrossRef Medline

Farr OM, Zhang S, Hu S, Matuskey D, Abdelghany O, Malison RT, Li CS (2014) The effects of methylphenidate on resting-state striatal, thalamic and global functional connectivity in healthy adults. Int J Neuropsychopharmacol 17:1177-1191. CrossRef Medline

Gamo NJ, Wang M, Arnsten AF (2010) Methylphenidate and atomoxetine enhance prefrontal function through $\alpha 2$-adrenergic and dopamine D1 receptors. J Am Acad Child Adolesc Psychiatry 49:1011-1023. CrossRef Medline

Gelman A, Hill J (2007) Data analysis using regression and multilevel/hierarchical models. New York: Cambridge UP.

Gill KE, Pierre PJ, Daunais J, Bennett AJ, Martelle S, Gage HD, Swanson JM, Nader MA, Porrino LJ (2012) Chronic treatment with extended release methylphenidate does not alter dopamine systems or increase vulnerability for cocaine self-administration: a study in nonhuman primates. Neuropsychopharmacology 37:2555-2565. CrossRef Medline

Grace AA, Floresco SB, Goto Y, Lodge DJ (2007) Regulation of firing of dopaminergic neurons and control of goal-directed behaviors. Trends Neurosci 30:220-227. CrossRef Medline

Hannestad J, Gallezot JD, Planeta-Wilson B, Lin SF, Williams WA, van Dyck CH, Malison RT, Carson RE, Ding YS (2010) Clinically relevant doses of methylphenidate significantly occupy norepinephrine transporters in humans in vivo. Biol Psychiatry 68:854-860. CrossRef Medline

Hong SB, Harrison BJ, Fornito A, Sohn CH, Song IC, Kim JW (2015) Functional dysconnectivity of corticostriatal circuitry and differential response to methylphenidate in youth with attention-deficit/hyperactivity disorder. J Psychiatry Neurosci 40:46-57. CrossRef Medline

Hutchison RM, Leung LS, Mirsattari SM, Gati JS, Menon RS, Everling S (2011) Resting-state networks in the macaque at 7 T. Neuroimage 56: 1546-1555. CrossRef Medline

Innis RB, Cunningham VJ, Delforge J, Fujita M, Gjedde A, Gunn RN, Holden J, Houle S, Huang SC, Ichise M, Iida H, Ito H, Kimura Y, Koeppe RA, Knudsen GM, Knuuti J, Lammertsma AA, Laruelle M, Logan J, Maguire RP, et al. (2007) Consensus nomenclature for in vivo imagine of reversibly binding radioligands. J Cereb Blood Flow Metab 27:1533-1539. CrossRef Medline

Jenkinson M, Bannister P, Brady M, Smith S (2002) Improved optimization for the robust and accurate linear registration and motion correction of brain images. Neuroimage 17:825-841. CrossRef Medline

Kelly C, de Zubicaray G, Di Martino A, Copland DA, Reiss PT, Klein DF, Castellanos FX, Milham MP, McMahon K (2009) L-dopa modulates functional connectivity in striatal cognitive and motor networks: a double-blind placebo-controlled study. J Neurosci 29:7364-7378. CrossRef Medline

Kiyatkin EA, Rebec GV (1996) Dopaminergic modulation of glutamateinduced excitations of neurons in the neostriatum and nucleus accumbens of awake, unrestrained rats. J Neurophysiol 75:142-153. CrossRef Medline

Kodama T, Kojima T, Honda Y, Hosokawa T, Tsutsui KI, Watanabe M (2017) Oral administration of methylphenidate (Ritalin) affects dopamine release differentially between the prefrontal cortex and striatum: a microdialysis study in the monkey. J Neurosci 37:2387-2394. CrossRef Medline

Krause J (2008) SPECT and PET of the dopamine transporter in attentiondeficit/hyperactivity disorder. Expert Rev Neurother 8:611-625. CrossRef Medline

Krugel LK, Biele G, Mohr PN, Li SC, Heekeren HR (2009) Genetic variation in dopaminergic neuromodulation influences the ability to rapidly and flexibly adapt decisions. Proc Natl Acad Sci U S A 106:17951-17956. CrossRef Medline

Lammertsma AA, Hume SP (1996) Simplified reference tissue model for PET receptor studies. Neuroimage 4:153-158. CrossRef Medline

Mach RH, Nader MA, Ehrenkaufer RL, Line SW, Smith CR, Gage HD, Morton TE (1997) Use of positron emission tomography to study the dynamics of psychostimulant-induced dopamine release. Pharmacol Biochem Behav 57:477-486. CrossRef Medline

Mantini D, Perrucci MG, Del Gratta C, Romani GL, Corbetta M (2007) 
Electrophysiological signatures of resting state networks in the human brain. Proc Natl Acad Sci U S A 104:13170-13175. CrossRef Medline

Margulies DS, Vincent JL, Kelly C, Lohmann G, Uddin LQ, Biswal BB, Villringer A, Castellanos FX, Milham MP, Petrides M (2009) Precuneus shares intrinsic functional architecture in humans and monkeys. Proc Natl Acad Sci U S A 106:20069-20074. CrossRef Medline

Moirano JM, Bezgin GY, Ahlers EO, Kötter R, Converse AK (2018) Rhesus macaque brain atlas regions aligned to an MRI template. Neuroinformatics. Advance online publication. Retrieved October 5, 2018. doi: 10.1007/s12021-018-9400-2.

Mueller S, Costa A, Keeser D, Pogarell O, Berman A, Coates U, Reiser MF, Riedel M, Möller HJ, Ettinger U, Meindl T (2014) The effects of methylphenidate on whole brain intrinsic functional connectivity. Hum Brain Mapp 35:5379-5388. CrossRef Medline

Mukherjee J, Yang ZY, Das MK, Brown T (1995) Fluorinated benzamide neuroleptics: III. Development of (S)-N-((1-allyl-2-pyrrolidinyl)methyl)-5(3-[ $\left.{ }^{18} \mathrm{~F}\right]$ fluoropropyl)-2, 3-dimethoxybenzamide as an improved dopamine D-2 receptor tracer. Nucl Med Biol 22:283-296. CrossRef Medline

Mukherjee J, Yang ZY, Lew R, Brown T, Kronmal S, Cooper MD, Seiden LS (1997) Evaluation of D-amphetamine effects on the binding of dopamine D-2 receptor radioligand, ${ }^{18} \mathrm{~F}$-fallypride in nonhuman primates using positron emission tomography. Synapse 27:1-13. CrossRef Medline

Nagano-Saito A, Leyton M, Monchi O, Goldberg YK, He Y, Dagher A (2008) Dopamine depletion impairs frontostriatal functional connectivity during a set-shifting task. J Neurosci 28:3697-3706. CrossRef Medline

Nir Y, Mukamel R, Dinstein I, Privman E, Harel M, Fisch L, Gelbard-Sagiv H, Kipervasser S, Andelman F, Neufeld MY, Kramer U, Arieli A, Fried I, Malach R (2008) Interhemispheric correlations of slow spontaneous neuronal fluctuations revealed in human sensory cortex. Nat Neurosci 11:1100-1108. CrossRef Medline

Ouchi Y, Yoshikawa E, Okada H, Futatsubashi M, Sekine Y, Iyo M, Sakamoto M (1999) Alterations in binding site density of dopamine transporter in the striatum, orbitofrontal cortex, and amygdala in early Parkinson's disease: compartment analysis for beta-CFT binding with positron emission tomography. Ann Neurol 45:601-610. CrossRef Medline

Paxinos G, Huang XF, Petrides M, Toga AW (2009) The rhesus monkey brain in stereotaxic coordinates, Ed 2. San Diego: Academic.

Peterson BS, Potenza MN, Wang Z, Zhu H, Martin A, Marsh R, Plessen KJ, Yu S (2009) An FMRI study of the effects of psychostimulants on defaultmode processing during Stroop task performance in youths with ADHD. Am J Psychiatry 166:1286-1294. CrossRef Medline

Populin LC (2005) Anesthetics change the excitation/inhibition balance that governs sensory processing in the cat superior colliculus. J Neurosci 25:5903-5914. CrossRef Medline

Rajala AZ, Henriques JB, Populin LC (2012) Dissociative effects of methylphenidate in nonhuman primates: trade-offs between cognitive and behavioral performance. J Cogn Neurosci 24:1371-1381. CrossRef Medline Rajala AZ, Jenison RL, Populin LC (2015) Decision making: effects of meth- ylphenidate on temporal discounting in nonhuman primates. J Neurophysiol 114:70-79. CrossRef Medline

Rolls ET, Thorpe SJ, Boytim M, Szabo I, Perrett DI (1984) Responses of striatal neurons in the behaving monkey: 3 . Effects of iontophoretically applied dopamine on normal responsiveness. Neuroscience 12:12011212. CrossRef Medline

Rubia K, Halari R, Cubillo A, Mohammad AM, Brammer M, Taylor E (2009) Methylphenidate normalises activation and functional connectivity deficits in attention and motivation networks in medication-naïve children with ADHD during a rewarded continuous performance task. Neuropharmacology 57:640-652. CrossRef Medline

Schlaepfer TE, Pearlson GD, Wong DF, Marenco S, Dannals RF (1997) PET study of competition between intravenous cocaine and (11C)raclopride at dopamine receptors in human subjects. Am J Psychiatry 154:12091213. CrossRef Medline

Shmuel A, Leopold DA (2008) Neuronal correlates of spontaneous fluctuations in fMRI signals in monkey visual cortex: implications for functional connectivity at rest. Hum Brain Mapp 29:751-761. CrossRef Medline

Soto PL, Wilcox KM, Zhou Y, Kumar A, Ator NA, Riddle MA, Wong DF, Weed MR (2012) Long-term exposure to oral methylphenidate or DLamphetamine mixture in peri-adolescent rhesus monkeys: effects on physiology, behavior, and dopamine system development. Neuropsychopharmacology 37:2566-2579. CrossRef Medline

Sprague RL, Sleator EK (1977) Methylphenidate in hyperkinetic children: differences in dose effects on learning and social behavior. Science 198: 1274-1276. CrossRef Medline

Tomasi D, Volkow ND, Wang GJ, Wang R, Telang F, Caparelli EC, Wong C, Jayne M, Fowler JS (2011) Methylphenidate enhances brain activation and deactivation responses to visual attention and working memory tasks in healthy controls. Neuroimage 54:3101-3110. CrossRef Medline

Vernaleken I, Peters L, Raptis M, Lin R, Buchholz HG, Zhou Y, Winz O, Rösch F, Bartenstein P, Wong DF, Schäfer WM, Gründer G (2011) The applicability of SRTM in $\left[{ }^{18} \mathrm{~F}\right]$ fallypride PET investigations: impact of scan durations. J Cereb Blood Flow Metab 31:1958-1966. CrossRef Medline

Volkow ND, Wang GJ, Fowler JS, Logan J, Franceschi D, Maynard L, Ding YS, Gatley SJ, Gifford A, Zhu W, Swanson JM (2002) Relationship between blockade of dopamine transporters by oral methylphenidate and the increases in extracellular dopamine: therapeutic implications. Synapse 43: 181-187. CrossRef Medline

Wargin W, Patrick K, Kilts C, Gualtieri CT, Ellington K, Mueller RA, Kraemer G, Breese GR (1983) Pharmacokinetics of methylphenidate in man, rat and monkey. J Pharmacol Exp Ther 226:382-386. Medline

Wise SP (2008) Forward frontal fields: phylogeny and fundamental function. Trends Neurosci 31:599-608. CrossRef Medline

Zimmer L (2009) Positron emission tomography neuroimaging for a better understanding of the biology of ADHD. Neuropharmacology 57:601607. CrossRef Medline 